\title{
Structural analyses and reverse Monte Carlo modeling of niobium oxide amorphous film prepared by sputtering method
}

\author{
Go SAJIKI ${ }^{\dagger}$, Yasuhiko BENINO*, Chinatsu OKI*, Koji OHARA**, Hiroshi OKANO ${ }^{* * *}$ and Tokuro NANBA* \\ Technological, educational supporting center in Takamatsu, National Institute of Technology, Kagawa College, Takamatsu, Japan \\ ${ }^{*}$ Graduate School of Environmental and Life Science, Okayama University, Okayama, Japan \\ ** Japan Synchrotron Radiation Research Institute, Sayo, Hyogo, Japan \\ *** General Education in Takamatsu, National Institute of Technology, Kagawa College, Takamatsu, Japan
}

\begin{abstract}
Structural analyses of niobium oxide $\left(\mathrm{NbO}_{x}\right)$ amorphous film prepared with a sputtering method have been performed by using synchrotron $\mathrm{X}$-ray radiation at SPring-8. The composition was determined as $\mathrm{Nb}_{2} \mathrm{O}_{5} \cdot 0.8 \mathrm{H}_{2} \mathrm{O}$ from the measurements of Rutherford back scattering, X-ray fluorescence, X-ray absorption near edge structure, and thermal desorption spectroscopy. Structural information was obtained by extended $X$-ray absorption fine structure and high energy X-ray diffraction measurements. It was supposed from the experimental data that $\mathrm{NbO}_{x}$ consisted of distorted $\mathrm{NbO}_{n}$ polyhedra connected by corner- and edge-sharing. Structural models were constructed with reverse Monte Carlo (RMC) simulations. In the RMC models, the structural characteristics were successfully reproduced, and $\mathbf{H}$ atoms were, however, randomly distributed. Then, bond valence sum (BVS) constraint was introduced to the RMC simulation. As the results, narrower distribution in BVS was achieved for all the constituent atoms, and distinct $\mathrm{OH}$ bonds were effectively generated in the RMC model.
\end{abstract}

(C2017 The Ceramic Society of Japan. All rights reserved.

Key-words: Structural analysis, Amorphous film, Niobium oxide, Synchrotron radiation, High energy X-ray diffraction, X-ray absorption fine structure, Reverse Monte Carlo simulation, Bond valence sum

[Received March 16, 2017; Accepted June 1, 2017]

\section{Introduction}

Among the renewable energies, such as wind, ${ }^{1)}$ terrestrial heat, ${ }^{2)}$ water $^{3)}$ and biomass, ${ }^{4)}$ solar energy ${ }^{5)}$ is unlimited and most suitable for power generation. Si-based solar cells have been developed and widely used so far. ${ }^{6)-8)}$ However, their conversion efficiency is not so high, and furthermore, there is a concern about insufficient supply of Si feedstock and soaring prices of crystalline silicon because demand for silicon for photovoltaic industry is increasing every year. ${ }^{9), 10)}$ Hence, new solar power generation devices have been explored. ${ }^{11)-15)}$ Photo-electrochemical cell (PEC) is one of the candidates among various photoelectric transducers. ${ }^{16), 17)}$ In PEC, electricity is generated due to photo irradiation, where hydrogen is also produced by water electrolysis. $\mathrm{TiO}_{2}$ has been extensively studied as a PEC material, ${ }^{18)-20}$ and recently, dye sensitized solar cells ${ }^{21)-23)}$ have been developed to achieve lower cost and production energy.

In the authors' group, $\mathrm{PEC}$ based on niobium oxide, $\mathrm{NbO}_{x}$ has been developed, where $\mathrm{NbO}_{x}$ was sputter-deposited on an Al-coated glass substrate. ${ }^{24)}$ In the PECs with a $\mathrm{NbO}_{x} / \mathrm{Al} /$ glass $\mid \mathrm{KNO}_{3}$ aq. $\mid \mathrm{Al} /$ glass structure, faint but stable electricity generation has been successfully observed during light irradiation. The maximum power density was obtained, when the $\mathrm{NbO}_{x}$ deposits were not in continuous film structure but in a discrete nano-island structure. It was concluded that the PEC reactions proceeded in the immediate vicinity of the boundary among the nano-islands of niobium oxide, substrate metal, and electrolyte solution. However, actual mechanisms of power generation have

\footnotetext{
Corresponding author: G. Sajiki; E-mail: sajiki@t.kagawa-nct. ac.jp

* Preface for this article: Dol http://doi.org/10.2109/jcersj2.125.P10-1
}

not been solved completely, because $\mathrm{NbO}_{x}$ deposits are amorphous $^{24)}$ and hence their atomic structures have been unknown. If the atomic structures of $\mathrm{NbO}_{x}$ deposits are clarified, their electronic structures will be also elucidated, and it is consequently expected that the power generation mechanism is revealed. It is also helpful to improve the efficiency of PECs.

Thus, the authors' group has investigated electronic and atomistic structures of $\mathrm{NbO}_{x}$ deposits based on optical absorption and photoelectron spectrometries, ${ }^{25)}$ in which density functional theory (DFT) calculations have been performed to interpret the experimental spectra based on the structure. In the DFT calculations, $\mathrm{Nb}_{2} \mathrm{O}_{5}$ crystals of B-, R-, and M-phases were chosen. The experimental XPS and UPS valence band spectra were broad, and no characteristic sharp peaks were observed. Among the investigated crystals, M-phase $\mathrm{Nb}_{2} \mathrm{O}_{5}$ showed better reproducibility, and it was supposed that broad distribution of $\mathrm{Nb}-\mathrm{O}$ bond length was responsible for the broad feature in the photoelectron spectra of $\mathrm{NbO}_{x}$ deposits.

Then, in the present study, detailed structural analyses of amorphous $\mathrm{NbO}_{x}$ deposits have been performed, where structural information was obtained by high energy X-ray diffraction (HEXRD) and X-ray absorption fine structure (XAFS) with synchrotron radiation. Structural models were constructed with a reverse Monte Carlo (RMC) simulation to reproduce the experimental information.

\section{Experiment}

$\mathrm{NbO}_{x}$ specimens with the thickness of $100 \mathrm{~nm}$ with a continuous structure were deposited on various substrates by an RF magnetron reactive sputtering method, where a metallic $\mathrm{Nb}$ was sputtered under a $0.39 \mathrm{~Pa}$ of an $\mathrm{Ar}: \mathrm{O}_{2}=1: 1$ mixture with an $\mathrm{RF}$ power of $200 \mathrm{~W}$ (more detailed conditions are given in else- 
where ${ }^{24)}$ ). An oxygen-free graphite sheet (PERMA-FOIL ${ }^{\circledR}$ ) was used as a substrate for the measurements of Rutherford back scattering (RBS) and X-ray fluorescence (XRF) to determine the composition. A quartz glass was used to estimate the density from X-ray reflectivity (XRR), gas desorption from thermal desorption spectroscopy (TDS), and local structure around $\mathrm{Nb}$ atom from XAFS measurement with a fluorescence method. For these measurements, $\mathrm{NbO}_{x}$ specimens of $100 \mathrm{~nm}$ thickness were used. As for XAFS measurement, $\mathrm{NbO}_{x}$ film with $5 \mathrm{~nm}$ thickness was also prepared to investigate the dependency of film thickness, and reagents of $\mathrm{Nb}, \mathrm{NbO}, \mathrm{Nb}_{2} \mathrm{O}_{3}, \mathrm{NbO}_{2}$, and $\mathrm{Nb}_{2} \mathrm{O}_{5}$ (Kojundo Chemical Lab. Co., Ltd.) were also used for comparison. For HEXRD measurement, $\mathrm{NbO}_{x}$ films of $200 \mathrm{~nm}$ were deposited on polymer films $\left(\right.$ Kapton $^{\circledR}$ ) with $50 \mu \mathrm{m}$ thickness with small X-ray absorption. Nine sheets of the polymer films with $\mathrm{NbO}_{x}$ deposits were stacked to obtain larger scattering intensity from the $\mathrm{NbO}_{x}$ deposits. The measurements of XRR, XAFS and HEXRD were performed in the beam lines of BL46XU, BL01B1 and BL04B2 at SPring-8, respectively. RMC simulation was carried out to obtain structural model reproducing the experimental data.

\section{Results and discussion}

\subsection{Composition and density}

As mentioned, $\mathrm{NbO}_{x}$ deposits were prepared with an RF sputtering method. Hence, the deviation from the stoichiometric composition of $\mathrm{Nb}_{2} \mathrm{O}_{5}$ was expected in the $\mathrm{NbO}_{x}$ deposits. Then, compositional analyses were performed to obtain accurate composition. From RBS measurement, the composition of $\mathrm{NbO}_{x}$ deposits was estimated as $\mathrm{O} / \mathrm{Nb}=2.9$, which was higher than the case of $\mathrm{Nb}_{2} \mathrm{O}_{5}$ with the $\mathrm{Nb}$ valence of +5 . Then, it was also evaluated by XRF using a reference sample $\left(\mathrm{Nb}_{2} \mathrm{O}_{5}\right.$, Micromatter $\mathrm{Co}$.), and after a thorough analysis, ${ }^{26), 27)}$ the same value of $\mathrm{O} / \mathrm{Nb}=2.9$ was obtained. It was supposed that the excess oxygen was present in chemically-adsorbed water or hydroxyl group. Then, TDS measurement was carried out to investigate the desorbed species during heating, from which desorption of water was confirmed at the temperature between $100-400^{\circ} \mathrm{C}$. From these results, the composition of $\mathrm{NbO}_{x}$ deposits was finally determined as $\mathrm{Nb}_{2} \mathrm{O}_{5}$. $0.8 \mathrm{H}_{2} \mathrm{O}$. According to the composition, XRR spectrum was analyzed to obtain the density of c.a. $4.5 \mathrm{~g} / \mathrm{cm}^{3}$.

\subsection{Local structure around $\mathrm{Nb}$ from XAFS analyses}

Figure 1 shows the results of Nb K-edge XAFS measurements, where difference in the XAFS spectra is quite small between the $\mathrm{NbO}_{x}$ deposits with different thicknesses. The similarity in the XAFS spectra suggests that the local atomic and electronic structures around $\mathrm{Nb}$ are not altered even when the thickness changes-from 5 to $100 \mathrm{~nm}$. In Fig. 1(a) of X-ray absorption near edge structure (XANES), the absorption edge shifts to higher energy side with increasing the valence number of niobium. The absorption edge of $\mathrm{NbO}_{x}$ deposits is close to that of $\mathrm{Nb}_{2} \mathrm{O}_{5}\left(\mathrm{~T}-\mathrm{Nb}_{8.4} \mathrm{O}_{21}\right)$ crystal, suggesting that $\mathrm{Nb}$ atoms in $\mathrm{NbO}_{x}$ deposits have a valence of +5 . In Fig. 1(a), a pre-edge peak at $\sim 18990 \mathrm{eV}$ is confirmed in $\mathrm{NbO}_{x}$ deposits. The pre-edge peak is generally described by tetrahedral $\mathrm{NbO}_{4}$ tetrahedra ${ }^{28)}$ and distorted $\mathrm{NbO}_{6}$ octahedra. ${ }^{29)}$ The pre-edge peak is also observed in the $\mathrm{Nb}_{2} \mathrm{O}_{5}$ crystal, which consists of $\mathrm{NbO}_{5}, \mathrm{NbO}_{6}$, and $\mathrm{NbO}_{7}$ polyhedra. ${ }^{30)}$ The $\mathrm{NbO}_{x}$ deposits have larger pre-edge peak in intensity than the $\mathrm{Nb}_{2} \mathrm{O}_{5}$ crystal, which suggests larger distortion of $\mathrm{NbO}_{n}$ polyhedra in the $\mathrm{NbO}_{x}$ deposits. From the X-ray absorption curves [Fig. 1(b)], extended X-ray absorption fine structure (EXAFS) spectra were obtained [Fig. 1(c)]. EXAFS spectra at
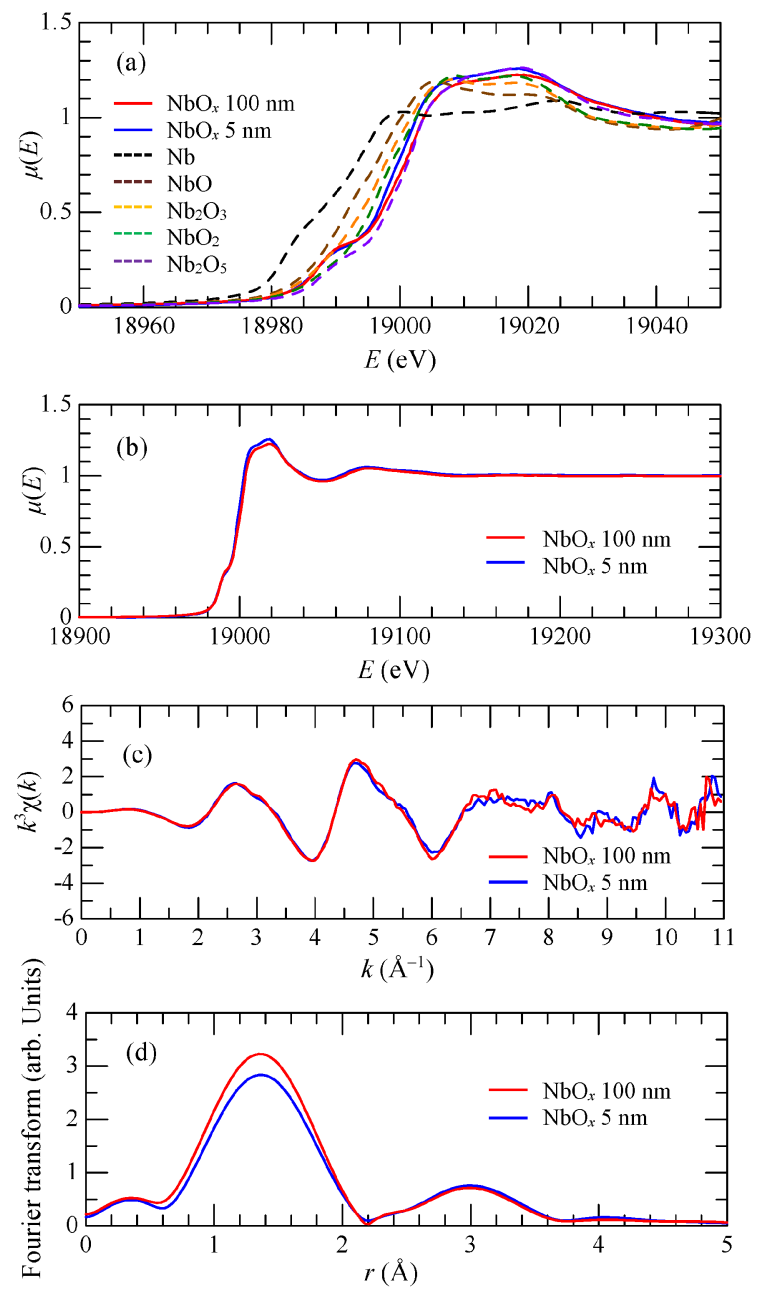

Fig. 1. Experimental results of XAFS measurements. (a) XANES spectra, (b) Absorption coefficients, $\mu(E)$ at a photon energy, $E$, (c) EXAFS spectra, $k^{3} \chi(k)$ (normalized absorption, $\chi(k)$ at a photoelectron wavevector, $k)$, and (d) magnitudes of Fourier transform of $k^{3} \chi(k)(k=$ 2-7 $\AA^{-1}$ ) for $\mathrm{NbO}_{x}$ deposits with different thicknesses.

$k=2-7 \AA^{-1}$ [Fig. 1(c)] were Fourier-transformed to obtain radial distribution. In the Fourier transform [Fig. 1(d)], peaks are observed at radius, $r=1.4$ and $3.0 \AA$, which are attributed to the nearest $\mathrm{Nb}-\mathrm{O}$ and $\mathrm{Nb}-\mathrm{Nb}$ pairs, respectively. The second peak is small as compared with the first peak, suggesting the structural disorder in the connection between $\mathrm{NbO}_{n}$ polyhedra.

\subsection{Short and medium range structures from HEXRD analyses}

Figure 2 shows the results of HEXRD measurements. Figure 2(a) indicates the HEXRD patterns of the stacked sheets of polymer substrates with $\mathrm{NbO}_{x}$ deposits (Curve A) and the sheets of polymer substrates without $\mathrm{NbO}_{x}$ deposits (Curve B). Scattering intensity curve of $\mathrm{NbO}_{x}$ deposits (Curve C) was obtained by subtracting Curve B from Curve A. In Curve C, peaks are clearly confirmed at the diffraction angle $2 \theta=\sim 4$ and $\sim 7^{\circ}$, which correspond to the peaks at $\sim 2$ and $\sim 4 \AA^{-1}$ of structure factor, $S(Q)$ in Fig. 2(b). The $S(Q)$ curve at higher $Q$ (reciprocal lattice vector) region is noisy, because the subtracted scattering intensities at higher $2 \theta$ region are small, and the $\mathrm{S} / \mathrm{N}$ ratio of $S(Q)$ is also small at higher $Q$ region [Fig. 2(b)]. Total correlation function, $T(r)$ given in Fig. 2(c) was obtained by the Fourier transform of $S(Q)$ at the $Q$ region of $0.5-15 \AA^{-1}$. In $T(r)$, 

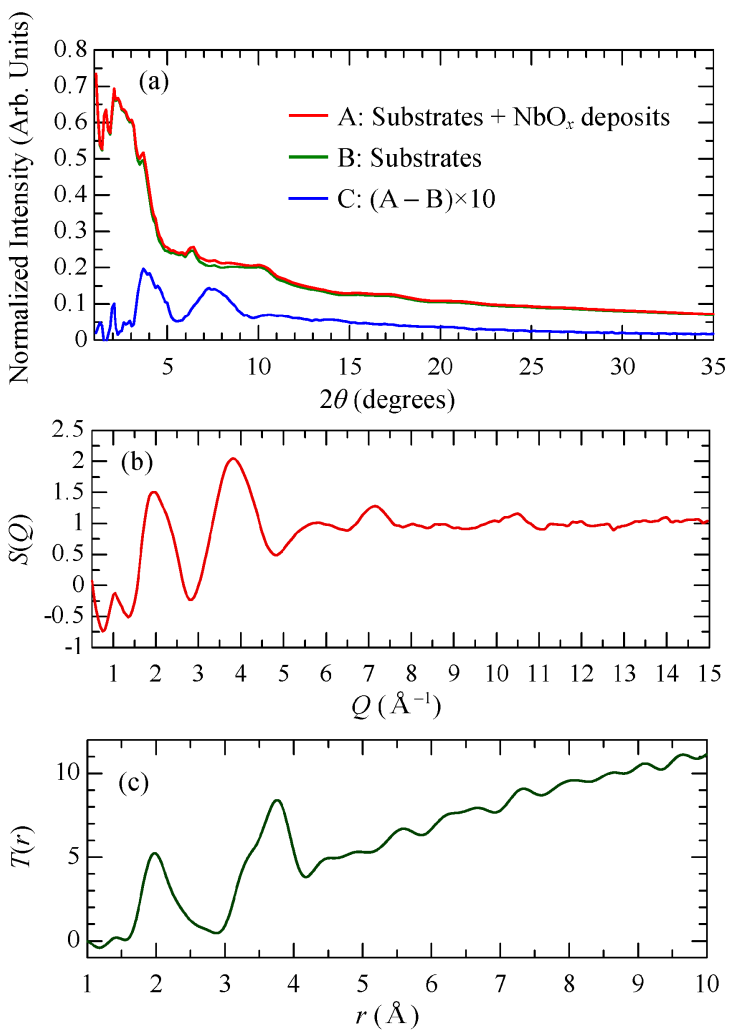

Fig. 2. Experimental results of HEXRD measurements. (a) Scattering intensity curves of stacked sheets of polymer substrates with $\mathrm{NbO}_{x}$ deposits (Curve A), sheets of polymer substrates without $\mathrm{NbO}_{x}$ deposits (Curve B), and $\mathrm{NbO}_{x}$ deposits obtained by subtraction (Curve C), (b) structure factor, $S(Q)$ and (c) total correlation function, $T(r)$

however, clear peaks are confirmed at $\sim 2 \AA$ attributed to the nearest $\mathrm{Nb}-\mathrm{O}$ pairs and $\sim 4 \AA$ ascribed by $\mathrm{Nb}-\mathrm{Nb}$ pairs in the neighboring $\mathrm{NbO}_{n}$ polyhedra. In the longer radial distance, $r>4.5 \AA$, the amplitude of fine structure decreases suddenly, which probably results from the structural disorder in the $\mathrm{NbO}_{n}$ polyhedral arrangement. Such the medium range structural disorder is also supposed from the Fourier transform of EXFAS spectra [Fig. 1(d)].

Differential correlation functions, $D(r)$ of some niobium oxide crystals were calculated from their structural parameters given in the literatures. ${ }^{30)-38)}$ Figure 3 shows the calculated $D(r)$, where experimental $D(r)$ of $\mathrm{NbO}_{x}$ deposit is also shown for comparison.

In $D(r)$ curves, a large peak is commonly confirmed at $\sim 3.9 \AA$, and another peak is seen at $\sim 3.4 \AA$ except for $\mathrm{B}-\mathrm{Nb}_{2} \mathrm{O}_{5}$ and $\mathrm{HNbO}_{3}$. These peaks are due to $\mathrm{Nb}-\mathrm{Nb}$ pairs in corner- and edgesharing $\mathrm{NbO}_{n}$ polyhedra, respectively. $\mathrm{B}-\mathrm{Nb}_{2} \mathrm{O}_{5}$ consists of corner- and edge-sharing $\mathrm{NbO}_{6}$ units with comparatively higher symmetry, ${ }^{31)}$ which results in large and symmetric $\mathrm{Nb}-\mathrm{Nb}$ peak at $\sim 3.7 \AA . \mathrm{HNbO}_{3}$ which consists of only corner-sharing $\mathrm{NbO}_{6}$ octahedra ${ }^{38)}$ has the closest composition to the amorphous $\mathrm{NbO}_{x}$ $\left(\mathrm{H}_{0.8} \mathrm{NbO}_{2.9}\right)$. However, the $3.4 \AA$ peak is recognized in $D(r)$ of $\mathrm{NbO}_{x}$, indicating the presence of edge-sharing $\mathrm{NbO}_{n}$ units in $\mathrm{NbO}_{x}$ and dissimilarity to $\mathrm{HNbO}_{3}$ in the connection form of $\mathrm{NbO}_{n}$ units. The dissimilarity to $\mathrm{HNbO}_{3}$ is also confirmed in the peak of $\mathrm{Nb}-\mathrm{O}$ pairs at $\sim 2.0 \AA$. In $\mathrm{HNbO}_{3}$, the peak is symmetric, and in $\mathrm{NbO}_{x}$, tailing to the longer side is recognized. Such the tailing of the $\mathrm{Nb}-\mathrm{O}$ peak is also seen in $\mathrm{N}-\mathrm{Nb}_{2} \mathrm{O}_{5}$ and $\mathrm{H}-\mathrm{Nb}_{2} \mathrm{O}_{5}$, where these crystals ${ }^{34), 35)}$ are constituted by distorted $\mathrm{NbO}_{6}$ octahedra. In the previous spectroscopic study, ${ }^{25)}$ DFT calculations

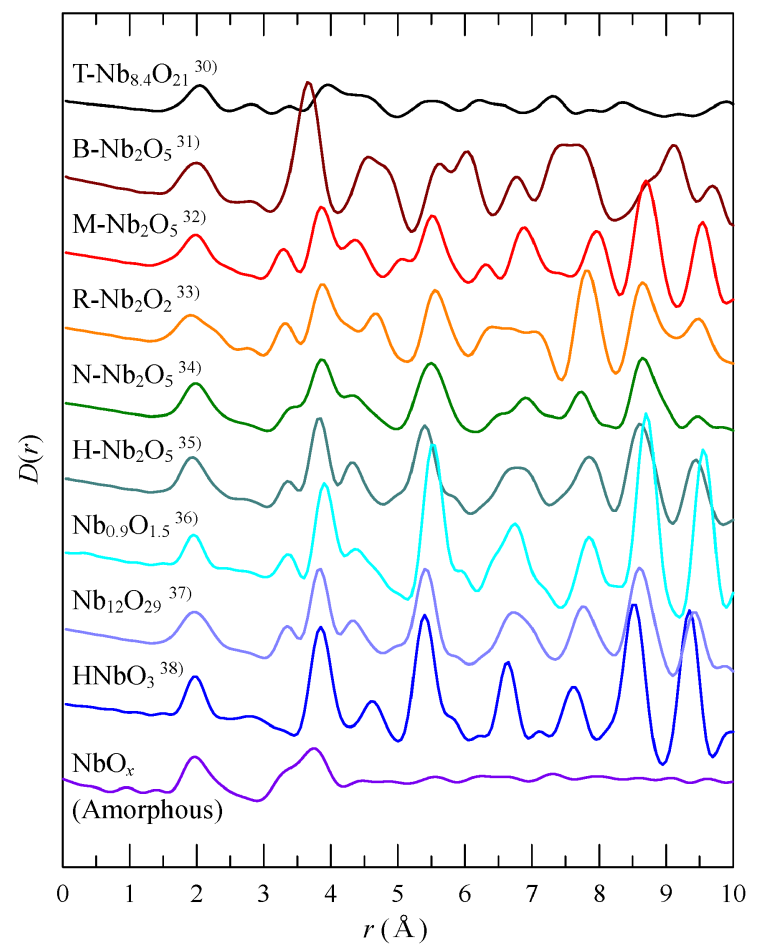

Fig. 3. Differential correlation functions, $D(r)$ calculated from niobium oxide crystals and $\mathrm{NbO}_{x}$ film.

suggested the structural similarity to $\mathrm{M}-\mathrm{Nb}_{2} \mathrm{O}_{5}$, and in $D(r)$, however, it is hard to say that $\mathrm{M}-\mathrm{Nb}_{2} \mathrm{O}_{5}$ shows the best agreement with $\mathrm{NbO}_{x}$. XANES spectra [Fig. 1(a)] suggests the structural similarity between the amorphous $\mathrm{NbO}_{x}$ film and $\mathrm{T}^{-\mathrm{Nb}_{8.4} \mathrm{O}_{21}}$ crystal, and in $D(r)$ curves, however, $\mathrm{T}^{-\mathrm{Nb}_{8.4} \mathrm{O}_{21}}$ crystal does not show the closest resemblance to $\mathrm{NbO}_{x}$. Presence of a large variety of $\mathrm{Nb}_{2} \mathrm{O}_{5}$-related polymorphs makes the structural analysis of $\mathrm{NbO}_{x}$ so difficult. In any case, it is consequently considered from XAFS and HEXRD analyses that amorphous $\mathrm{NbO}_{x}$ consists of distorted $\mathrm{NbO}_{n}$ polyhedra connected by corner- and edge-sharing.

\subsection{RMC structural modeling}

In $\mathrm{RMC}$ structural simulation, 1175 atoms $(\mathrm{Nb}=250, \mathrm{O}=$ 725 , and $\mathrm{H}=200$ ) were put in a simulation box with a side length of $23.42 \AA$. The RMC constraints used were as follows: $S(Q)$ at $Q=1.5-10 \AA^{-1}, k^{3} \chi(k)$ at $k=4.3-6.5 \AA^{-1}$, minimum interatomic distances of $\mathrm{Nb}-\mathrm{Nb}=2.90, \mathrm{Nb}-\mathrm{O}=1.50, \mathrm{Nb}-\mathrm{H}=1.50$, $\mathrm{O}-\mathrm{O}=1.60, \mathrm{O}-\mathrm{H}=0.80$, and $\mathrm{H}-\mathrm{H}=1.50 \AA$. In the simulation of $k^{3} \chi(k)$, single-scattering of $\mathrm{Nb}-\mathrm{Nb}, \mathrm{Nb}-\mathrm{O}$, and $\mathrm{Nb}-\mathrm{H}$ pairs was assumed, because the second peak in Fourier transform of $k^{3} \chi(k)$ [Fig. 1(d)] was small, suggesting little contribution of multiplescattering to EXAFS in amorphous $\mathrm{NbO}_{x}$.

As mentioned, hydrogen atoms are present in $\mathrm{NbO}_{x}$ deposits, and it is quite difficult to reproduce their position even though using HEXRD and EXAFS. It is supposed that bond valence sum (BVS) constraint is suitable to avoid chemically-unstable or highly-distorted coordination structures around atoms because BVS depends on bond length and coordination number. ${ }^{39), 40)}$ Then, in the present study, BVS constraint of $\mathrm{Nb}=+5, \mathrm{O}=-2$, and $\mathrm{H}=+1$ was also introduced to $\mathrm{RMC}$ simulation. In the RMC simulation, an RMC code, RMCprofile ${ }^{41)}$ was chosen to apply the constraints of HEXRD, EXAFS, and BVS.

Figure 4 shows the RMC model obtained by using the BVS constraint in addition to HEXRD and EXAFS constraints. It is 


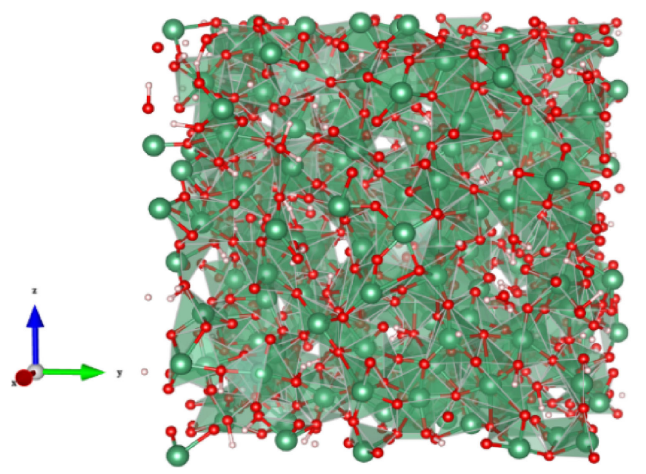

Fig. 4. RMC model of the amorphous niobium oxide, $\mathrm{Nb}_{2} \mathrm{O}_{5} \cdot 0.8 \mathrm{H}_{2} \mathrm{O}$ optimized with BVS constraint. Green: niobium, red: oxygen, and pink: hydrogen. $\mathrm{Nb}-\mathrm{O}$ and $\mathrm{O}-\mathrm{H}$ bonds are drawn for the respective pairs within 2.8 and $1.5 \AA$.
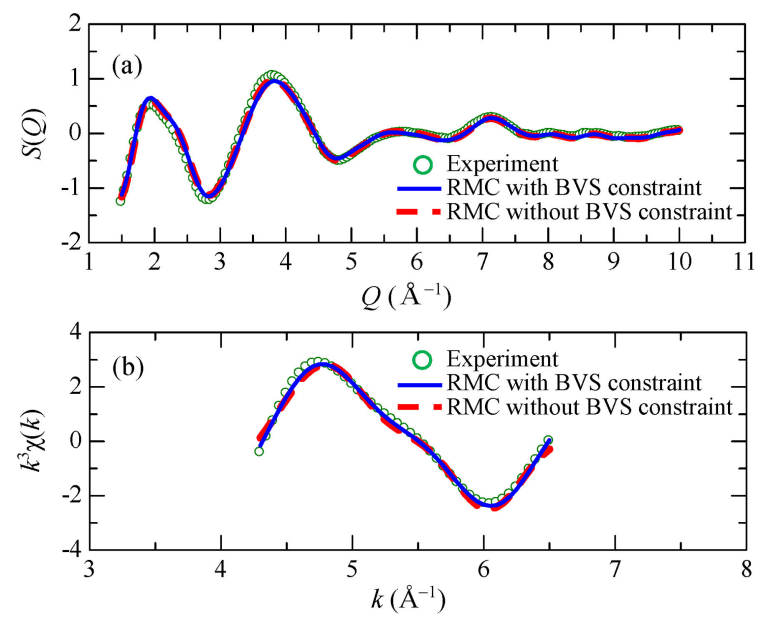

Fig. 5. (a) Structure factors, $S(Q)$ and (b) EXAFS spectra, $k^{3} \chi(k)$ obtained from experiments and RMC models.

difficult to find apparent differences in the arrangement of $\mathrm{Nb}$ and $\mathrm{O}$ atoms from the model without BVS constraint. In the model shown in Fig. 4, small numbers of $\mathrm{H}_{2} \mathrm{O}$ molecules are found, which are mostly present as a ligand of $\mathrm{Nb}$ atoms and rarely separate from $\mathrm{NbO}_{n}$ polyhedra. As shown in Fig. 5, the experimental $S(Q)$ and $k^{3} \chi(k)$ spectra are successfully reproduced by the RMC simulations regardless of BVS constraint. As for BVS shown in Fig. 6, however, large difference is confirmed between the results with and without BVS constraint. As for $\mathrm{Nb}$ and $\mathrm{O}$ atoms, distribution of BVS becomes narrower when applying BVS constraint. Average BVS increases commonly with BVS constraint. The changes in average BVS of $\mathrm{Nb}$ and $\mathrm{O}$ atom are comparatively small compared with that of $\mathrm{H}$ atom. Average BVS of $\mathrm{H}$ atom is quite small without BVS constraint.

Figure 7 shows partial pair distribution functions, $g(r)$ of RMC models. Significant change in $g(r)$ is not observed except for $\mathrm{O}-\mathrm{H}$. As shown in Fig. 6, BVS distribution of $\mathrm{Nb}$ and $\mathrm{O}$ atoms become narrower with BVS constraint, and it is hence expected that the first $g(r)$ peak for $\mathrm{Nb}-\mathrm{O}$ becomes narrower with BVS constraint, and the change in $g(r)$ is, however, quite small after applying BVS constraint, which is also the case in $S(Q)$ and $k^{3} \chi(k)$ spectra as shown in Fig. 5, suggesting that BVS is more sensitive to the local structure than $g(r), S(Q)$ and $k^{3} \chi(k)$ spectra. In the $g(r)$ of $\mathrm{Nb}-\mathrm{Nb}$ pair, two peaks are successfully reproduced at $3-4 \AA$, which correspond to the peaks observed in $T(r)$
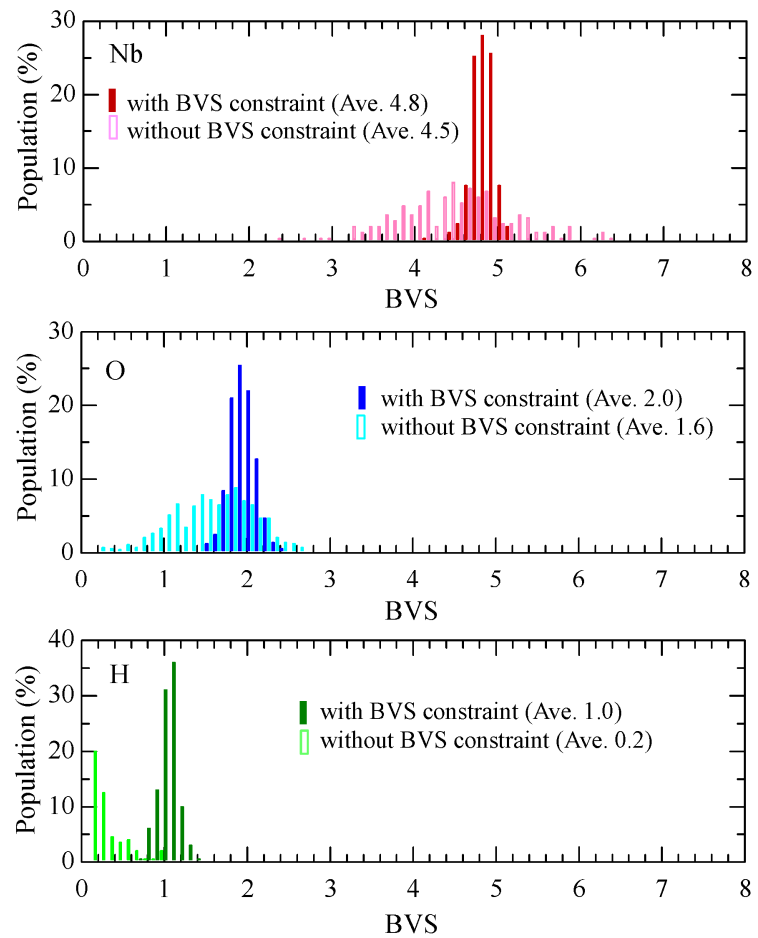

Fig. 6. Distribution of bond valence sum, BVS of the elements in RMC models.

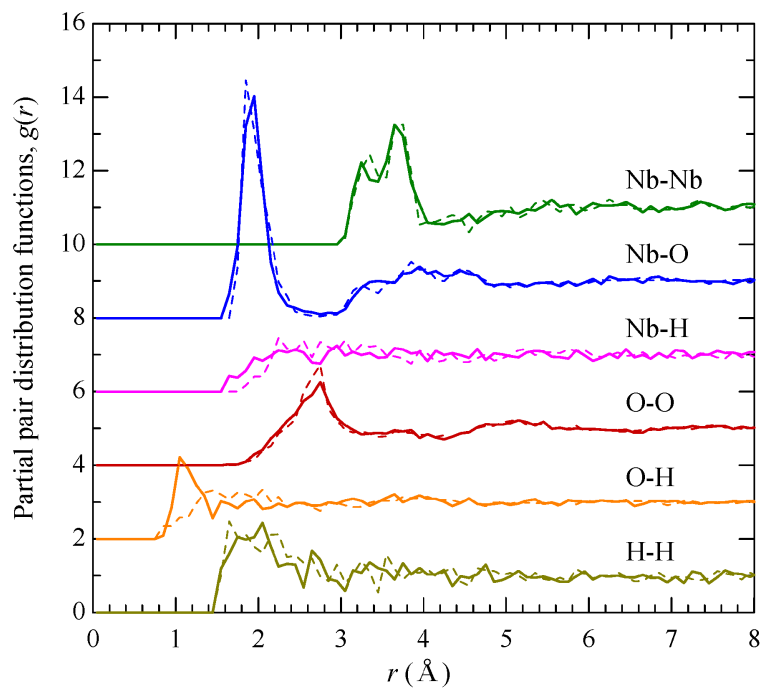

Fig. 7. Partial pair distribution functions $g(r)$ in RMC models (solid lines: with BVS constraint, broken lines: without BVS constraint).

[Fig. 2(c)] and $D(r)$ (Fig. 3). The shorter and longer $\mathrm{Nb}-\mathrm{Nb}$ pairs result from edge- and corner-sharing $\mathrm{NbO}_{n}$ polyhedra in the RMC models, respectively. In the $g(r)$ of $\mathrm{Nb}-\mathrm{O}$ pair, tailing of the first peak at $2 \AA$ to longer $r$ in $D(r)$ is also reproduced. As for O$\mathrm{H}$ pair, however, BVS constraint results in a significant difference in $g(r)$, that is, no characteristic $\mathrm{O}-\mathrm{H}$ peaks are observed from the RMC model without BVS constraint, which results from random distribution of $\mathrm{H}$ atoms. On the other hand, a peak is clearly confirmed at $\sim 1.0 \AA$ from the RMC model with BVS constraint. The increase in shorter $\mathrm{O}-\mathrm{H}$ bonds results in the larger increase in BVS of $\mathrm{H}$ atoms (Fig. 6). Thus, it is suggested that BVS constraint is effective to improve structural order around atoms with less structural information such as hydrogen. The longest dis- 

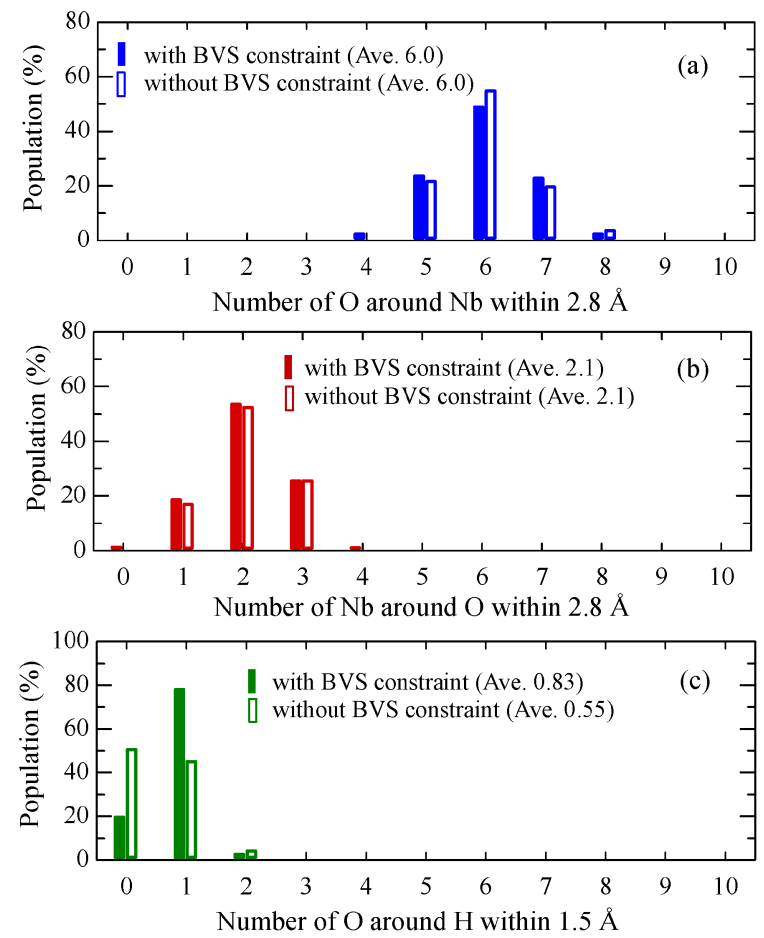

Fig. 8. Distribution of coordination numbers in RMC models. Average coordination numbers are given in the parentheses.

tances of $\mathrm{Nb}-\mathrm{O}$ and $\mathrm{O}-\mathrm{H}$ bonds are estimated as 2.8 and $1.5 \AA$, respectively, from the first peak edge of longer side in $g(r)$ for $\mathrm{Nb}-\mathrm{O}$ and $\mathrm{O}-\mathrm{H}$ pairs, and the distances are used as cut-off distances in bond determination (Figs. 4 and 8).

Figure 8 shows distribution of coordination numbers. $\mathrm{NbO}_{5}$, $\mathrm{NbO}_{6}$ and $\mathrm{NbO}_{7}$ polyhedra are abundant in $\mathrm{RMC}$ models, and by using BVS constraint, slightly broader distribution around $\mathrm{Nb}$ is obtained, that is, $\mathrm{NbO}_{6}$ unit decreases while $\mathrm{NbO}_{5}$ and $\mathrm{NbO}_{7}$ units increases in population. However, the change in coordination number distribution against BVS constraint is much smaller than the change in BVS distribution (Fig. 6), which also suggests that BVS is quite sensitive to local structure. In the case of number of $\mathrm{O}$ around $\mathrm{H}$ shown in Fig. 8(c), significant change is observed as expected from the change in BVS of $\mathrm{H}$ (Fig. 6). In the RMC model without BVS constraint, $\sim 50 \%$ of $\mathrm{H}$ atoms have no neighbors of $\mathrm{O}$ atoms within $1.5 \AA$. In the RMC model with BVS constraint, however, $\sim 80 \%$ of $\mathrm{H}$ have one $\mathrm{O}$ atom as a neighbor, but only a few percent of $\mathrm{H}$ atoms are used for $\mathrm{H}_{2} \mathrm{O}$ molecules. Among $\mathrm{O}$ atoms in $\mathrm{OH}$ bonds, $54 \%$ was non-bridging oxygen which had one neighboring $\mathrm{Nb}$ atom, indicating nonselective bond formation of $\mathrm{H}$ atoms with $\mathrm{O}$ atoms. Connection form of $\mathrm{NbO}_{n}$ units in the RMC models was also examined; fractions of corner-, edge-, and face-sharing were 73,25 , and $2 \%$, respectively.

By using RMC simulation, a structural model was successfully obtained, where structural characteristics of amorphous $\mathrm{NbO}_{x}$ film were also revealed. Electronic structure of the RMC model should be evaluated to clarify photo-electrochemical properties. The RMC model produced in this study consists of 1175 atoms, and it is too large to perform band calculation. Hence, different theoretical calculation is required for the estimation of electronic structure, and it should be a future task.

\section{Conclusion}

The structural analyses of amorphous $\mathrm{NbO}_{x}$ deposited by sputtering method have been performed, where structural information was obtained from XAFS and HEXRD measurements by using synchrotron radiation. From RBS and XRF analyses, $\mathrm{O} / \mathrm{Nb}$ atomic ratio was estimated as 2.9, and from XANES analysis, however, valence state of $\mathrm{Nb}$ atoms was identified as +5 . Then, it was supposed that the excess oxygen atoms were present in $\mathrm{OH}$ group, and $\mathrm{H}_{2} \mathrm{O}$ desorption during heat-treatment was successfully confirmed in TDS measurement. Hence, the composition of $\mathrm{NbO}_{x}$ deposits was finally determined as $\mathrm{Nb}_{2} \mathrm{O}_{5} \cdot 0.8 \mathrm{H}_{2} \mathrm{O}$

In XANES spectra, a pre-edge peak was found, and its intensity was larger than that of $\mathrm{Nb}_{2} \mathrm{O}_{5}$ crystal, from which larger distortion of $\mathrm{NbO}_{n}$ polyhedra was suggested in amorphous $\mathrm{NbO}_{x}$. Such the distortion was also suggested from the asymmetrical $\mathrm{Nb}-\mathrm{O}$ peak in differential correlation function, $D(r)$. In $D(r)$, the peak due to $\mathrm{Nb}-\mathrm{Nb}$ pairs was split into two components, which were attributed to the corner- and edge-sharing $\mathrm{NbO}_{n}$ units. In the radial distribution obtained from EXAFS spectra, the second peak due to $\mathrm{Nb}-\mathrm{Nb}$ pairs with smaller intensity was observed, suggesting the disordered arrangement of the neighboring $\mathrm{NbO}_{n}$ units.

The structural models have been constructed with RMC simulation, in which HEXRD and EXAFS data were successfully reproduced. Structural characteristics found in the above analyses were also reproduced in the RMC model. However, hydrogen atoms were randomly distributed in the structural model. Then, BVS constraint was also introduced to the RMC simulation, and in partial pair distribution function, $g(r)$ of $\mathrm{O}-\mathrm{H}$ pair, a clear peak appeared at $r=\sim 1 \AA$. At that time, local structures around $\mathrm{Nb}$ and $\mathrm{O}$ atoms showed no significant change in $D(r)$, and in BVS, however, drastic change was confirmed in these atoms, that is, BVS distribution became quite narrower. It was consequently suggested that BVS constraint was effective to improve the regularity in local structure around the atoms especially with less structural information, such as $\mathrm{H}$ atom in the present case.

In the present study, however, no experimental information for the structural roles of $\mathrm{H}$ atoms has been obtained, and it is necessary to examine local structure of $\mathrm{H}$ atoms. Furthermore, it is also indispensable to investigate the electronic structure of amorphous $\mathrm{NbO}_{x}$. Based on the knowledges acquired, power generation mechanism of $\mathrm{NbO}_{x}$ should be clarified, and it should be possible to design $\mathrm{NbO}_{x}$-based PECs with higher conversion efficiency.

Acknowledgments The synchrotron radiation experiments were performed at BL04B2, BL01B1, BL46XU, and BL13XU in SPring-8 with the approval of the Japan Synchrotron Radiation Research Institute (JASRI) (Proposal No. 2013B1657, 2014A1631, 2014A1694, and 2014B1732, respectively). The graphite sheet (PERMA-FOIL ${ }^{\circledR}$ ) was provided by Toyo Tanso Co., Ltd. The authors would like to thank Dr. Shunichi Hishita of National Institute for Materials Science for the RBS measurement. The authors wish to acknowledge Dr. Shinji KOHARA of National Institute for Materials Science, for him help in RMC simulation of this study.

\section{References}

1) B. R. Karthikeya, P. S. Negi and N. Srikanth, Renew. Energ., 87, 403-414 (2016).

2) M. Pujola, L. P. Ricard and G. Bolton, Geothermics, 57, 39-55 (2015).

3) L. Perković, T. Novosel, T. Pukšec, B. Ćosić, M. Mustafa, G. Krajačić and N. Duić, Energ. Convers. Manage., 110, 249-259 (2016).

4) C. Wang, L. Zhang, Y. Chang and M. Pang, Energy Policy, 84, $155-165$ (2015).

5) W. Yaïci and E. Entchev, Renew. Energ., 86, 302-315 (2016). 
6) D. Irishik, K. Imamura and H. Kobayashi, Sol. Energy Mater. Sol. Cells, 141, 1-6 (2015).

7) K. Hara, S. Jonai and A. Masuda, Sol. Energy Mater. Sol. Cells, 140, 361-365 (2015).

8) K. Islam, F. I. Chowdhury, A. K. Okyay and A. Nayfeh, Sol. Energy, 120, 257-262 (2015).

9) F. Cao, K. Chen, J. Zhang, X. Ye, J. Li, S. Zou and X. Su, Sol. Energy Mater. Sol. Cells, 141, 132-138 (2015).

10) S. Pizzini, Sol. Energy Mater. Sol. Cells, 94, 1528-1533 (2010).

11) M. S. Guney, Renew. Sust. Energ. Rev., 57, 776-785 (2016).

12) G. Reginato, M. Calamante, A. Dessì, A. Mordini, M. Peruzzini and L. Zani, J. Organomet. Chem., 771, 117-123 (2014).

13) P. B. L. Chaurasia, N. Panja and K. Kendall, Renew. Energ., 36, 3305-3312 (2011).

14) S. H. Park, S. J. Lee, J. H. Lee, J. Kal, J. Hahn and H. K. Kim, Org. Electron., 30, 112-121 (2016).

15) M. Sugawara, Y. Arakawa and K. Tanabe, Semiconductor Lasers (2013) 272-315.

16) A. Zyoud, R. S. Al-Kerm, R. S. Al-Kerm, M. Waseem, H. S. H. Mohammed, D. Park, G. Campet, N. Sabli and H. S. Hilal, Electrochim. Acta, 174, 472-479 (2015).

17) L. Roza, M. Y. A. Rahman, A. A. Umar and M. M. Salleh, J. Alloy. Compd., 618, 153-158 (2015).

18) A. Fujishima and K. Honda, Nature, 238, 37-38 (1972).

19) P. R. Mishra, P. K. Shukla and O. N. Srivastava, Int. J. Hydrogen Energ., 32, 1680-1685 (2007).

20) A. Kusior, A. Wnuk, A. T. Zajac, K. Zakrzewska and M. Radecka, Int. J. Hydrogen Energ., 40, 4936-4944 (2015).

21) S. P. Lim, A. Pandikumar, H. N. Lim and N. M. Huang, Sol. Energy, 125, 135-145 (2016).

22) R. Li, Y. Zhao, R. Hou, X. Ren, S. Yuan, Y. Lou, Z. Wang, D. Li and L. Shi, J. Photoch. Photobio. A, 319-320, 62-69 (2016).

23) L. Kong, Y. Bao, W. Guo, L. Cheng, J. Du, R. Liu, Y. Wang, X. Fan and C. Tao, Appl. Surf. Sci., 363, 323-327 (2016).
24) G. Sajiki, Y. Benino, T. Nanba and H. Okano, Mater. Sci. Appl., 6, 292-309 (2015).

25) C. Oki, G. Sajiki, S. Sakida, Y. Benino and T. Nanba, J. Ceram. Soc. Jpn., 124, 1221-1225 (2016).

26) B. L. Henke, E. M. Gullikson and J. C. Davis, Atom. Data Nucl. Data, 54, 181-342 (1993).

27) T. Shiraiwa and N. Fujino, Jpn. J. Appl. Phys., 5, 886-899 (1966).

28) A. Corma, F. X. Llabrés i Xamena, C. Prestipino, M. Renz and S. Valencia, J. Phys. Chem. C, 113, 11306-11315 (2009).

29) I. Nakai, J. Akimoto, M. Imafuku, R. Miyawaki, Y. Sugitani and K. Koto, Phys. Chem. Miner., 15, 113-124 (1987).

30) M. Kikuchi, K. Kusaba, E. Bannai, K. Fukuoka, Y. Syono and K. Hiraga, Jpn. J. Appl. Phys., 24, 1600-1606 (1985).

31) F. Laves, W. Petter and H. Wulf, Naturwissenschaften, 51, 633-634 (1964).

32) W. Mertin, S. Andersson and R. Gruehn, J. Solid State Chem., 1, 419-424 (1970).

33) R. Gruehn, J. Less-Common Met., 11, 119-126 (1966).

34) S. Andersson, Z. Anorg. Allg. Chem., 351, 106-112 (1967).

35) H. F. McMurdie, M. C. Morris, E. H. Evans, B. Paretzkin, N. W. Wong, Y. Zhang and C. R. Hubbard, Powder Diffr., 1, 334-345 (1986).

36) V. V. Klechkovskaya, N. V. Troitskaya and Z. G. Pinsker, Sov. Phys. Crystallogr., 10, 28-35 (1965).

37) R. Norin, Acta Chem. Scand., 20, 871-880 (1966).

38) J. L. Fourquet, M. F. Renou and R. D. Pape, Rev. Chim. Miner., 21, 383-390 (1984).

39) I. D. Brown, "The Chemical Bond in Inorganic Chemistry: The Bond Valence Model (International Union of Crystallography Monographs on Crystallography)", Oxford University Press (2006) p. 230.

40) I. D. Brown and D. Altermatt, Acta Crystallogr. B, 41, 244 247 (1985).

41) M. G. Tucker, D. A. Keen, M. T. Dove, A. L. Goodwin and Q. Hui, J. Phys.-Condens. Mat., 19, 335218 (2007). 